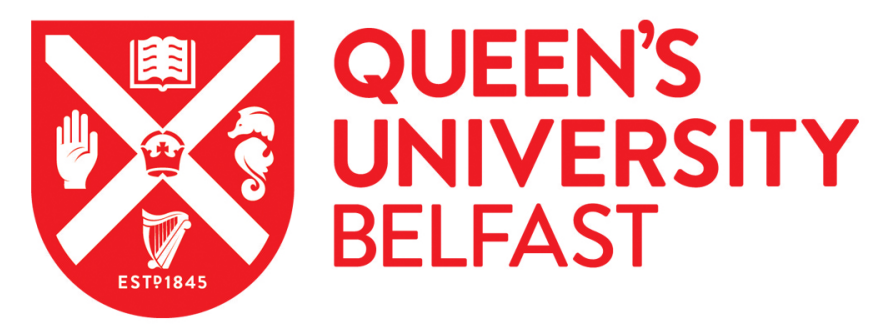

\title{
Impact of patient characteristics on edentulous subjects' preferences for prosthodontic rehabilitation with implants
}

Rodrigues Leles, C., Rocha Dias, D., Eduardo Nogueira, T., McKenna, G., Schimmel, M., \& Jordao, L. M. R. (2019). Impact of patient characteristics on edentulous subjects' preferences for prosthodontic rehabilitation with implants. clinical oral implants research. https://doi.org/10.1111/clr.13414

Published in:

clinical oral implants research

Document Version:

Peer reviewed version

Queen's University Belfast - Research Portal:

Link to publication record in Queen's University Belfast Research Portal

Publisher rights

(c) 2019 John Wiley \& Sons A/S. Published by John Wiley \& Sons Ltd. This work is made available online in accordance with the publisher's policies. Please refer to any applicable terms of use of the publisher.

\section{General rights}

Copyright for the publications made accessible via the Queen's University Belfast Research Portal is retained by the author(s) and / or other copyright owners and it is a condition of accessing these publications that users recognise and abide by the legal requirements associated with these rights.

Take down policy

The Research Portal is Queen's institutional repository that provides access to Queen's research output. Every effort has been made to ensure that content in the Research Portal does not infringe any person's rights, or applicable UK laws. If you discover content in the Research Portal that you believe breaches copyright or violates any law, please contact openaccess@qub.ac.uk. 


\section{Impact of patient characteristics on edentulous subjects' preferences for prosthodontic rehabilitation with implants}

Cláudio Rodrigues Leles, School of Dentistry, Federal University of Goias, Goiania, Goias, Brazil

Danilo Rocha Dias, School of Dentistry, Federal University of Goias, Goiania, Goias, Brazil

Túlio Eduardo Nogueira, School of Dentistry, Federal University of Goias, Goiania, Goias, Brazil

Gerald McKenna, Centre for Public Health, Queen's University, Belfast, United Kingdom

Martin Schimmel, School of Dental Medicine, University of Bern, Bern, Switzerland

Lidia Moraes Ribeiro Jordão, School of Dentistry, Federal University of Goias, Goiania, Goias, Brazil

Running title: Edentulous patients' preferences for implant treatments

Corresponding author:

Dr. Cláudio Rodrigues Leles. Department of Oral Rehabilitation, School of Dentistry, Federal University of Goias. Praça Universitária, esquina com Primeira Avenida, Setor Universitário, CEP 74605-220. Goiania, Goias, Brazil. Phone/Fax: +55 6232096052 e-mail: claudio_leles@ufg.br

Keywords: patient preference, complete denture, overdenture, implant supported denture, dental implants

C.R.L. conceived the study, supervised data collection, performed data analysis and drafted the manuscript. D.R.D. drafted the manuscript and participated in data analysis. L.M.R.J., T.E.N., G.M.K and M.S. participated in data analysis/interpretation and critically revised the manuscript. 


\section{ABSTRACT}

Objective: The aim of this study was to assess the influence of patient characteristics on edentulous subjects' preferences for different prosthodontic treatments with implants. Materials and Methods: A cross-sectional study was carried out with 131 edentulous subjects referred for treatment at a university clinic. Participants received detailed information about available treatment options, and were asked to rank their preferences among three alternatives for rehabilitation of the maxilla and mandible: conventional dentures (CD), 2implant retained overdentures (IOD) or 4-implant fixed dentures (IFD). Individual data and prosthodontic-related variables were assessed through interviews. Oral health-related quality of life impacts were measured using the Brazilian version of the Oral Health Impact Profile for edentulous subjects (OHIP-Edent). Descriptive statistics, bivariate tests, and binary and multinomial logistic regressions were used for data analysis. Results: The majority of participants chose CD as their most preferred treatment for the maxilla $(45.8 \%)$, while IFD was the most prevalent choice for the mandible (38.9\%). Regression analysis showed that the OHIP-Edent "oral pain and dysfunction" (OPD) domain scores were positively associated with $I O D$ preference for the maxilla $(O R=1.31$; $p=0.010)$ and mandible $(O R=1.46 ; p=0.002)$, and with IFD preference for the mandible $(O R=1.20 ; p=0.031)$. Subjects with lower levels of formal education and those with lower income levels were less likely to choose IFD. Conclusion: Level of education, income and perceived quality of life impacts are potentially predictive variables of edentulous patients' preference for rehabilitation with implants. These factors may constitute important aspects to be considered by clinicians when treatment planning for edentulous patients. 


\section{INTRODUCTION}

Although implant retained prostheses are likely to provide improvements in oral function and comfort for edentulous subjects, many patients still refuse implant therapy and choose conventional removable dentures instead (Cooper, 2009; Ellis, et al., 2011; Müller, Salem, Barbezat, Herrmann \& Schimmel, 2012). Costs and concerns about surgery are usually reported as main reasons for patients' preferences regarding implant treatment options (Narby, Kronström, Söderfeldt, \& Palmqvist, 2008; Ellis, et al., 2011). However, a variety of other factors may also play an important role for choosing less invasive and more conservative treatment alternatives (Leles, Ferreira, Vieira, Campos \& Silva, 2011). This is exemplified when implant treatment is offered free of charge or with subsided costs, but yet the refusal rates remain high (Walton \& MacEntee, 2005).

Besides external influences, such as professional advice and previous information (Korsch, Robra \& Walther, 2015; Wang, Gao \& Lo, 2015), a range of individual factors may influence patients' decisions before undergoing treatment (Ellis, et al., 2011; Müller, et al., 2012). In many cases there is a considerable distance between treatment acceptance and the decision to actually undergo treatment, and patients demonstrate distinct predispositions to accept different interventions. Previous studies with subjects presenting with a wide range of prosthodontic treatment needs showed that individuals' intention and behavior towards treatment is mediated by their perceived comfort in performing the particular behavior. This in turn is determined by the total set of accessible control beliefs (perceived behavioral control), which includes perception of costs, opportunity costs, perceived need, and access to dental care (Vieira, Castro e Silva, Nogueira \& Leles, 2015; Vieira, Silva, Nogueira \& Leles, 2016).

Similarly to the individual variability in patient treatment-seeking behavior, edentulous patients also diverge when they are asked to choose different options for prosthodontic rehabilitation. In a previous study which aimed to capture the different factors influencing edentulous patients' preferences for treatment using conventional or implant-retained dentures, technical and clinical 
issues played a major role in treatment decisions and patient preferences (Leles, et al., 2011). Moreover, social/financial status and oral-related quality of life (OHRQoL) may also be important factors that affect patients' preferences and should be factored into clinical decision-making.

Individual preferences for different rehabilitation strategies, including implant interventions, may vary amongst edentulous patients and influence greatly the likelihood of choosing or refusing a specific treatment option. Thus, the aim of this study was to assess the influence of a range of patient factors, including socioeconomic determinants, on edentulous subjects' preferences for prosthodontic rehabilitation options in the maxilla and mandible. The hypothesis tested in this study was that underlying patient reported factors are predictive of edentulous patients' preferences for conventional denture treatment and treatments with implants.

\section{MATERIAL AND METHODS}

This cross-sectional study recruited a non-probabilistic sample, including consecutive patients referred for treatment with conventional complete dentures in the School of Dentistry at the Federal University of Goias, Goiania, Brazil. All participants were completely edentulous and referred by dentists from the local public health system. The study protocol was registered (\#027688) and approved by the local research ethics committee (protocol 072/2007), and all participants were provided with a written patient information sheet and signed a written consent form. This paper has been written to comply with the STROBE guidelines.

Participants provided sociodemographic data including age, gender, marital status, monthly income and level of education to a trained research assistant. For analysis of financial status, income data was converted into a ratio/multiple of the Brazilian national minimum wage (BMW) at the time of data collection (BRL\$880 in 2016). Previous and current experiences with removable dentures were assessed by interviewing patients about types of prosthodontic treatment delivered, age at time of first permanent tooth loss, denture use and satisfaction 
with current dentures. Satisfaction was measured by a single dichotomous question. The Brazilian version of the Oral Health Impact Profile for Edentulous Subjects (OHIP-Edent) questionnaire (Souza, et al., 2010) was administrated to measure the OHRQoL of the participants.

Participants received comprehensive information about three potential treatment options for managing their complete edentulism: conventional complete dentures (CD), 2-implant retained overdentures (IOD) and 4-implant fixed dentures (IFD). All participants were provided with illustrated printed brochures with clinical photographs and simple descriptions of main features of each treatment modality (including surgical stages, comparative level of complexity, clinical time, cost of treatment, removability and expected stability and retention of the prosthesis), and models of edentulous arches (maxillary and mandibular) with their corresponding prostheses and implants.

Participants were then asked to rank their preference for the three treatment options (CD, IOD and IFD), in descending order for the maxilla and mandible separately. The first choice was presumed as the 'preferred' treatment (which they certainly would accept) and the third choice the 'refused' treatment (which they certainly would avoid).

Descriptive statistics were used to summarize the participants' socioeconomic characteristics and their reported preferences for the different treatment options. Bivariate tests (chi-square, independent t-test and one-way ANOVA) were used for comparison of groups according to treatment preferences. Regression analyses were used to assess the association between independent factors and the outcome variables (patient preference for maxillary and mandibular rehabilitation). Multiple binary logistic regression and multinomial logistic regression were used for the outcome variables categorized into two (conventional and implant treatments) or three (CD, IOD and IFD) groups, respectively. For all regression analyses, CD was considered the reference category. Statistical significance was set at $p<0.05$. IBM-SPSS 24.0 software was used for all data analysis. 


\section{RESULTS}

The study sample included 131 participants. Data collection occurred during different periods between 2008 and 2016. A descriptive report of participants' characteristics, denture use and satisfaction is detailed in Table 1. The majority of participants reported low levels of formal education $(49.5 \%$ had $<4$ years) and predominantly low monthly income ( $77.1 \%$ had individual income $\leq 2$ BMWs). Concerning denture use, $88.5 \%$ and $73.3 \%$ were currently wearing maxillary and mandibular conventional complete dentures, respectively, but only $55 \%$ reported to be satisfied with the current dentures.

Figure 1 illustrates the reported preferences according to the "preferred" and the "refused" treatments for the maxilla and mandible. CD was rated as the most preferred treatment for the maxilla by $45.8 \%$ of participants compared to $35.9 \%$ in the mandible. Overall, IFD was the most preferred treatment for the mandible $(38.9 \%)$. A statistically significant difference in the proportion of preferred and refused treatments for the maxilla and mandible was only detected for IFD $(p=0.01)$.

Bivariate comparative analyses of individual variables amongst the participants are detailed in Table 2. Participants' treatment preferences for the maxilla differed in groups as defined by age and level of education $(p<0.001)$, income $(p<0.01)$, satisfaction with current dentures $(p<0.05)$ and the OHIP-Edent "oral pain and dysfunction" (OPD) domain $(p<0.01)$, whereas preference for the mandible was related to the level of education $(p<0.001)$, income $(p<0.05)$ and the OHIP-Edent OPD domain $(p<0.01)$.

Variables were included in the logistic regression model which assessed associations between independent variables and the outcome (participant's treatment preference). Binary logistic regression considered patients' preferences dichotomized as conventional treatment (CD) and implant treatments (IOD+IFD). Crude and adjusted regression models are reported in Table 3, in which higher level of education, higher income and higher OHIPEdent/OPD domain scores were significantly associated with preference for implant treatments for both the maxilla and mandible. 
Multiple multinomial regression (Table 4) showed that OHIP-Edent/OPD domain scores were significantly associated with IOD preference for the maxilla $(O R=1.31 ; p=0.010)$ and the mandible $(O R=1.46 ; p=0.002)$. Preference for IFD was associated with the level of education, in which subjects of lower educational attainment were less likely to prefer IFD for the maxilla $(O R=0.16$; $p=0.001)$ and mandible $(O R=0.21 ; p=0.002)$. These preferences were also associated with income level, in which subjects with lower and intermediate income levels were less likely to prefer IFD for both the maxilla and mandible $(p<0.05)$. A positive association was also found between IFD and OHIPEdent/OPD domain scores for the mandible $(O R=1.20 ; p=0.031)$.

\section{DISCUSSION}

The findings of this study indicate that in a sample of predominantly older, lowincome edentulous subjects with low levels of formal education preferred treatment options differ for the edentulous maxilla and mandible. An interesting finding is that, although IFD have been recognized as a highly effective way to improve patient satisfaction, masticatory function and oral and general wellbeing of edentate adults, a large percentage of participants still ranked CD as their preferred treatment option. In addition, socioeconomic factors and perceived impacts on oral health-related quality of life played an important role in patients' preferences.

This study has a number of positive aspects, as it is a study which specifically explored a very important aspect of individualized treatment planning for edentulous patients. Furthermore, a range of validated instruments were used. And the number of patients included was considered sufficient on the basis of the number of events-per-variable in logistic regression modeling. On the other hand, one underlying limitation is that not all the treatment options were immediately available to the patients in the study as only treatment with $C D$ is available within the public health system in Brazil. In addition, although participants were given extensive information on what is involved in providing each of these treatments, including the surgical and prosthodontic aspects of 
implant treatments, the study methods did not reproduce the actual clinical settings where such treatments would be delivered. Future studies with a prospective design are needed to identify the gaps between need (both normative and perceived), demand, and actual utilization of dental care, as well as to measure the effective demand need to be addressed to improve the oral care delivery system (Pradeep, et al., 2016).

Despite the aforementioned benefits of dental implants, many patients still tended to prefer $C D$, especially for the maxilla. This finding may be due to the disparity between the quantitatively measured outcomes in clinical research and the subjectivity of patients' perceptions and their own criteria for treatment decisions. In other words, patients may prefer one treatment instead of another not because it has a superior outcome, but because they find such treatment more acceptable (McPherson, Britton \& Wennberg, 1997).

Clinical studies often focus on the efficacy and effectiveness of a treatment based on the estimates of expected change in oral health, but its acceptance and adoption by clinicians, patients and the general public depend on other factors including economic issues (Esfandiari, et al, 2009). This is particularly important in implant therapy as patient costs remain very high. In addition, randomized clinical trials are influenced by the emotional responses to treatment assignment, which may influence the estimates of treatment effectiveness. An underestimation of effectiveness will occur if more patients express a preference for a treatment which is considered inferior. Furthermore, the patients' "disappointment" at having been assigned a non-preferred treatment may be reflected in their ratings of satisfaction (McPherson, et al., 1997; Awad, Shapiro, Lund \& Feine, 2000). Patients' preferences have a major influence on their decision to not participate in randomized trials and affects drop-outs or non-compliance rate along the trial, reducing the general applicability of the results (Awad, et al., 2000).

The results of this study show that individual factors related to socioeconomic considerations play a major role in patient's preferences. Those with higher levels of education and higher incomes were more likely to opt for implant treatment, particularly IFD. These variables are closely related to individual 
accessibility to information and affordability of consumption items. Chowdhary, Mankani \& Chandraker (2010) conducted a survey to investigate the willingness to consider treatment with oral implants in urban India and found that, from those respondents who had heard about oral implants, $24 \%$ would definitely get implants if needed, and $53 \%$ were likely to get the treatment. Those who did not agree to undergo implant treatment, did so due to the high cost of implants $(85 \%)$ or because they required more information about the procedure $(15 \%)$. As a result of high patient costs associated with dental implants the need for dental insurance coverage has been advocated as a way to improve treatment accessibility (Chowdhary, et al., 2010). The role of treatment cost on clinical decision-making also reinforces the importance of cost-effectiveness studies comparing competing treatment options for the edentulous patient.

However, whilst public awareness and acceptance of dental implants is high, especially in younger individuals (Zimmer, Zimmer, Williams \& Liesener, 1992), there are still misconceptions regarding costs, which must be resolved in clinical practice (Rustemeyer \& Bremerich, 2007). In this study, all participants were complete denture wearers or had no dentures. It can therefore be assumed that many had little prior experience and understanding of implants. Unrealistic expectations are frequently found amongst some patients, which may lead to dissatisfaction with the final prosthodontic outcome (Yao, Tang, Gao, McGrath \& Mattheos, 2014). Although participants received comprehensive information before data collection, they may also have been influenced by information from laypersons, family, and other dentists, as well as from the widely available content via the internet and social media. General information may have limited quality assurance and is often misleading or contains inappropriate content, leading to communication bias and unmet expectations with treatment (Yao, et al., 2014).

Adequate counseling and information about treatment options may have an important influence on the decision-making process, especially if complex and extensive implant procedures are required. Korsch et al., (2015) observed that in cases of extensive treatment, more time after the implant counseling session is needed for patients to make their decision. In addition, patients with a stronger ambivalence toward implant intervention are more likely to refuse the 
intervention and have more questions during the counseling appointments than patients who chose implant treatment (Korsch, et al., 2015). Since lacking knowledge is one of the main reasons for implant refusal, the dentist is still the main source of reliable information about dental implants (Müller et al. 2012) and improved communication between the dentist and the patient may lead to a greater patient acceptance of dental implants as a treatment option (Pommer, et al., 2011).

In general, younger subjects are significantly more accepting of dental implants as a treatment modality than older individuals (Zimmer, et al., 1992). However, old age as such is not associated with negative attitudes towards implants, although limited knowledge, cost, psychological reasons and the need of surgical intervention have been associated with higher rates of implant refusal (Müller, et al., 2012). In this study, the influence of age on patients' preferences was only observed in the bivariate analysis, which suggests a higher preference for $C D$ and IOD in older subjects. This finding corroborates the use of less complex treatments or less invasive implant interventions for older patients (Müller, et al., 2012).

Clinical studies consistently show increased satisfaction and improvement in quality of life measures after insertion of new and more comfortable dentures (Elis, Pelekis \& Thomason, 2007) or after treatment with implants (Emami, Heydecke, Rompré, de Grandmont \& Feine, 2009). Participants with greater impacts on oral health-related quality of life, particularly related to the "oral pain and dysfunction" (OPD) domain, were more likely to prefer IOD and IFD treatments. Since the OPD domain refers to complaints such as ill-fitting and uncomfortable dentures and sore spots (Souza, et al., 2010), this finding suggests that denture wearers unsatisfied with denture-specific aspects related to low denture stability tend to prefer implant rather than conventional treatments.

\section{CONCLUSIONS}


In summary, the study findings suggest that edentulous subjects' preference in favor of conventional or implant treatments will vary between individuals and is affected by socioeconomic and clinical predisposing factors. Patient preferences also showed different features for the maxilla and mandible. Levels of formal education, income and perceived oral health-related quality of life impacts were identified as factors associated with patients' preference for treatment with implants and may be considered as relevant aspects for shared decision-making about prosthodontic rehabilitation for the edentulous patient.

\section{CONFLICT OF INTEREST AND SOURCE FUNDING STATEMENT}

None of the authors does report any conflict of interest related to the study, and there were no external funding sources for this research. 


\section{REFERENCES}

Awad, M. A., Shapiro, S. H., Lund, J. P., \& Feine, J. S. (2000). Determinants of patients' treatment preferences in a clinical trial. Community Dentistry and Oral Epidemiology, 28, 119-125. https://doi.org/10.1034/j.16000528.2000.028002119.x

Chowdhary, R., Mankani, N., \& Chandraker, N. K. (2010). Awareness of dental implants as a treatment choice in urban Indian populations. The International Journal of Oral \& Maxillofacial Implants, 25, 305-308.

Cooper, L. F. (2009). The current and future treatment of edentulism. Journal of Prosthodontics, 18, 116-122. https://doi.org/10.1111/j.1532-849X.2009.00441.x

Ellis, J. S., Pelekis, N. D., \& Thomason, J. M. (2007). Conventional rehabilitation of edentulous patients: the impact on oral health-related quality of life and patient satisfaction. Journal of Prosthodontics, 16, 37-42. https://doi.org/10.1111/j.1532-849X.2006.00152.x

Ellis, J. S., Levine, A., Bedos, C., Mojon, P., Rosberger, Z., Feine, J., \& Thomason, J. M. (2011). Refusal of implant supported mandibular overdentures by elderly patients. Gerodontology, 28, 62-68. https://doi.org/10.1111/j.17412358.2009.00348.x

Emami, E., Heydecke, G., Rompré, P. H., de Grandmont, P., \& Feine, J. S. (2009). Impact of implant support for mandibular dentures on satisfaction, oral and general health-related quality of life: a meta-analysis of randomizedcontrolled trials. Clinical Oral Implants Research, 20, 533-544. https://doi.org/10.1111/j.1600-0501.2008.01693.x

Esfandiari, S., Lund, J. P., Penrod, J. R., Savard, A., Thomason, J. M., \& Feine, J. S. (2009). Implant overdentures for edentulous elders: study of patient preference. Gerodontology, 26, 3-10. https://doi.org/10.1111/j.17412358.2008.00237.x

Korsch, M., Robra, B. P., \& Walther, W. (2015). Implant counseling and information: questions, predictors, and decision-making of patients before 
implant therapy. Clinical Oral Implants Research, 26, e47-e50. https://doi.org/10.1111/clr.12329

Leles, C. R., Ferreira, N. P., Vieira, A. H., Campos, A. C., \& Silva, E. T. (2011). Factors influencing edentulous patients' preferences for prosthodontic treatment. Journal of Oral Rehabilitation, 38, 333-339. https://doi.org/10.1111/j.1365-2842.2010.02158.x

McPherson, K., Britton. A. R., \& Wennberg, J. E. (1997). Are randomized controlled trials controlled? Patient preferences and unblind trials. Journal of the Royal Society of Medicine, 90, 652-656.

Müller, F., Salem, K., Barbezat, C., Herrmann, F. R., \& Schimmel, M. (2012). Knowledge and attitude of elderly persons towards dental implants. Gerodontology, 29, e914-e923. https://doi.org/10.1111/j.17412358.2011.00586.x

Narby, B., Kronström, M., Söderfeldt, B., \& Palmqvist, S. (2008). Changes in attitudes toward desire for implant treatment: a longitudinal study of a middleaged and older Swedish population. International Journal of Prosthodontics, 21, 481-485.

Pradeep, Y., Chakravarty, K. K., Simhadri, K., Ghenam, A., Naidu, G. M., \& Vundavalli, S. (2016). Gaps in need, demand, and effective demand for dental care utilization among residents of Krishna district, Andhra Pradesh, India. Journal of International Society of Preventive \& Community Dentistry, 6, S116121. https://doi.org/10.4103/2231-0762.189737

Pommer, B., Zechner, W., Watzak, G., Ulm, C., Watzek, G., \& Tepper, G. (2011). Progress and trends in patients' mindset on dental implants. II: implant acceptance, patient-perceived costs and patient satisfaction. Clinical Oral Implants Research, 22, 106-112. https://doi.org/10.1111/j.16000501.2010.01969.x

Rustemeyer, J., \& Bremerich, A. (2007). Patients' knowledge and expectations regarding dental implants: assessment by questionnaire. International Journal 
of Oral and Maxillofacial Surgery, 36, 814-817. https://doi.org/10.1016/j.ijom.2007.05.003

Souza, R. F., Leles, C. R., Guyatt, G. H., Pontes, C. B., Della Vecchia, M. P., \& Neves, F. D. (2010). Exploratory factor analysis of the Brazilian OHIP for edentulous subjects. Journal of Oral Rehabilitation, 37, 202-208. https://doi.org/10.1111/j.1365-2842.2009.02043.x

Vieira, A. H., Castro e Silva, D., Nogueira, T. E., \& Leles, C. R. (2016). Predictors of Prosthodontic Treatment-Related Behavior Using the Theory of Planned Behavior Framework. International Journal of Prosthodontics, 29, 139141.

Vieira, A. H., E Silva, D. C., Nogueira, T. E, \& Leles, C. R. (2015). Exploring motivations to seek and undergo prosthodontic care: a cross-sectional study in a Brazilian adult sample. Patient Preference and Adherence, 9, 803-809. https://doi.org/10.2147/PPA.S81645

Yao, J., Tang, H., Gao, X. L., McGrath, C., \& Mattheos, N. (2014). Patients' expectations to dental implant: a systematic review of the literature. Health and Quality of Life Outcomes, 12, 153. https://doi.org/10.1186/s12955-014-0153-9

Walton, J. N., \& MacEntee, M. I. (2005). Choosing or refusing oral implants: a prospective study of edentulous volunteers for a clinical trial. International Journal of Prosthodontics, 18, 483-488.

Wang, G., Gao, X., \& Lo, E. C. (2015). Public perceptions of dental implants: a qualitative study. Journal of Dentistry, 43, 798-805. https://doi.org/10.1016/j.jdent.2015.04.012

Zimmer, C. M., Zimmer. W. M., Williams, J., \& Liesener, J. (1992). Public awareness and acceptance of dental implants. International Journal of Oral \& Maxillofacial Implants, 7, 228-232. 
Figure legends

Fig. 1 Frequency distribution of edentulous individuals' preferences according to the "preferred" and the "refused" treatments for the maxilla and mandible. Available options were conventional complete dentures (CD), implant overdentures (IOD) and implant fixed dentures (IFD). 
Table 1. Descriptive characteristics of participants $(n=131)$

\begin{tabular}{|c|c|c|}
\hline Variable & Categories & $\mathrm{n}(\%)$ \\
\hline Gender & $\begin{array}{l}\text { Male } \\
\text { Female }\end{array}$ & $\begin{array}{l}60(45.8) \\
71(54.2)\end{array}$ \\
\hline Age & $33.4-84.3($ Min - Max $)$ & $57.6(12.4)^{*}$ \\
\hline Marital status & $\begin{array}{l}\text { Single } \\
\text { Married } \\
\text { Divorced } \\
\text { Widow } \\
\text { Not reported }\end{array}$ & $\begin{array}{l}11(8.4) \\
80(61.1) \\
10(7.6) \\
22(16.8) \\
8(6.1)\end{array}$ \\
\hline Level of education & $\begin{array}{l}\text { Illiterate } \\
\text { Incomplete lower secondary } \\
\text { Complete lower secondary } \\
\text { Incomplete upper secondary } \\
\text { Complete upper secondary } \\
\text { Complete higher }\end{array}$ & $\begin{array}{l}11(9.8) \\
52(39.7) \\
29(22.1) \\
22(16.8) \\
15(11.5) \\
2(1.5)\end{array}$ \\
\hline $\begin{array}{l}\text { Monthly income (in Brazilian } \\
\text { minimum wages) }\end{array}$ & $\begin{array}{l}\leq 1 \\
>1 \text { and } \leq 2 \\
>2 \text { and } \leq 3\end{array}$ & $\begin{array}{l}19(14.5) \\
82(62.6) \\
17(13.0)\end{array}$ \\
\hline & $\begin{array}{l}>3 \\
\text { Does not know }\end{array}$ & $\begin{array}{l}5(3.9) \\
8(6.1)\end{array}$ \\
\hline $\begin{array}{l}\text { Current use of complete } \\
\text { conventional dentures }\end{array}$ & $\begin{array}{l}\text { Maxilla } \\
\text { Mandible }\end{array}$ & $\begin{array}{l}116(88.5) \\
96(73.3)\end{array}$ \\
\hline $\begin{array}{l}\text { Satisfaction with current } \\
\text { dentures }\end{array}$ & $\begin{array}{l}\text { Yes } \\
\text { No } \\
\text { Does not know / Not applicable }\end{array}$ & $\begin{array}{l}72(55.0) \\
42(32.1) \\
17(12.9)\end{array}$ \\
\hline
\end{tabular}

${ }^{*}$ Mean (standard deviation) 
Table 2. Results of bivariate analysis between treatment preferences for maxilla/mandible and the independent variables. Data expressed as absolute frequencies (and percentage) and Chi-square test p-value.

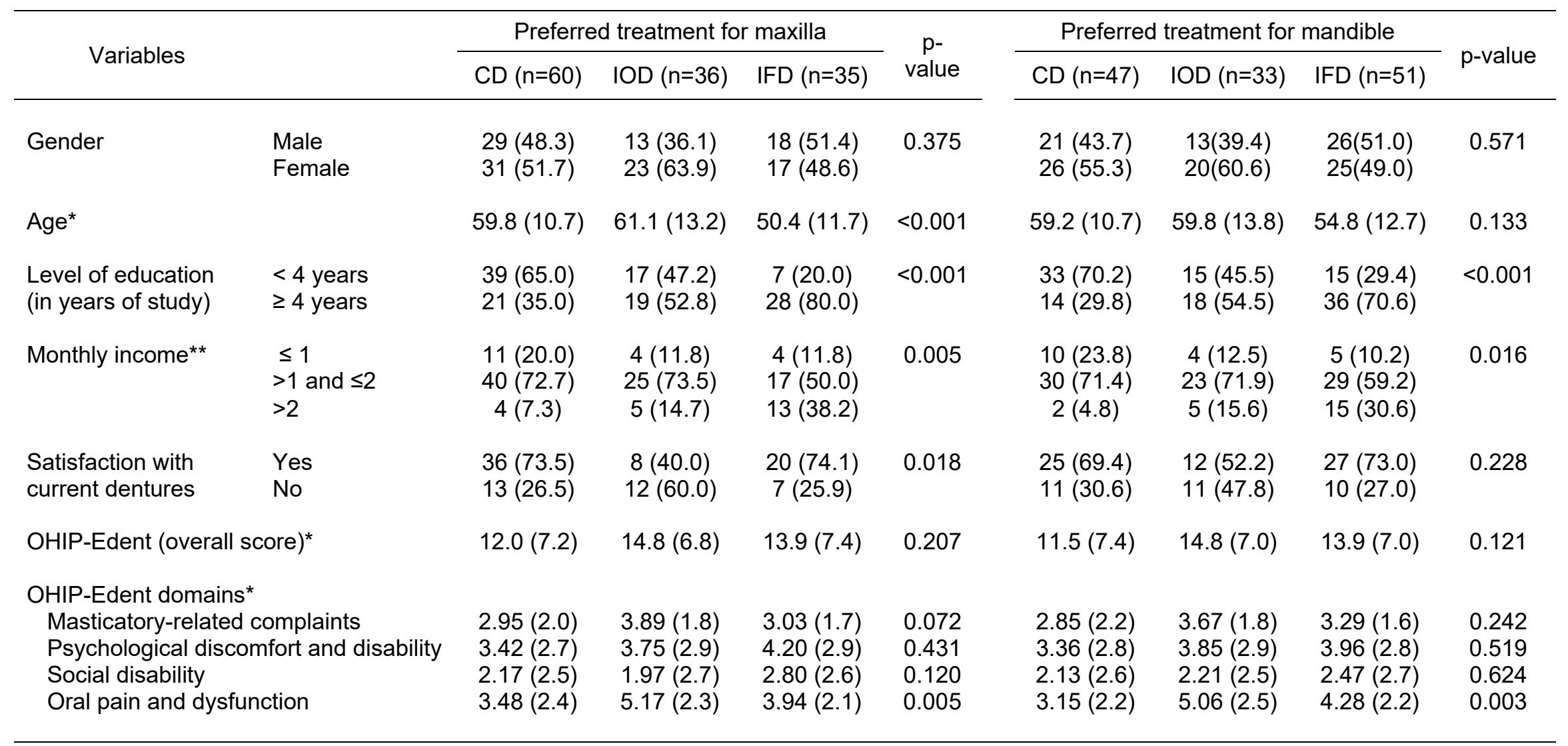

${ }^{*}$ Data expressed as means (and standard deviation) and p-values (Kruskal-Wallis test)

** In Brazilian minimum wages (BMW) 
Table 3. Binary logistic regression for independent variables associated with implant treatment preferences (implant overdenture + fixed implant denture). Conventional dentures (CD) treatment was set as the reference category. Only significant associations are shown for the adjusted regression models

\begin{tabular}{|c|c|c|c|c|c|}
\hline \multirow{2}{*}{ Arch } & \multirow{2}{*}{$\begin{array}{l}\text { Independent variables (target } \\
\text { category) }\end{array}$} & \multicolumn{2}{|c|}{ Crude } & \multicolumn{2}{|c|}{ Adjusted } \\
\hline & & OR $(95 \% \mathrm{Cl})$ & $p$-value & OR $(95 \% \mathrm{Cl})$ & p-value \\
\hline \multirow[t]{6}{*}{ Maxilla } & Age & $0.97(0.95-1.00)$ & 0.069 & & \\
\hline & Gender (female) & $1.21(061-2.41)$ & 0.593 & & \\
\hline & Level of education ( $\geq 4$ years) & $3.64(1.76-7.50)$ & $<0.001$ & $3.17(1.43-7.04)$ & 0.005 \\
\hline & Monthly income (higher) & $6.19(1.50-25.5)$ & 0.012 & $4.83(1.09-21.4)$ & 0.038 \\
\hline & OPD domain (OHIP-Edent) & $1.23(1.05-1.44)$ & 0.012 & $1.21(1.01-1.46)$ & 0.036 \\
\hline & Satisfaction with denture (No) & $1.88(0.79-4.45)$ & 0.151 & & \\
\hline \multirow[t]{6}{*}{ Mandible } & Age & $0.98(0.96-1.01)$ & 0.284 & & \\
\hline & Gender (female) & $1.07(0.52-2.20)$ & 0.847 & & \\
\hline & Level of education ( $\geq 4$ years) & $4.24(1.97-9.15)$ & $<0.001$ & $3.80(1.59-9.13)$ & 0.003 \\
\hline & Monthly income (higher) & $11.1(2.01-61.4)$ & 0.006 & $8.91(1.45-54.8)$ & 0.018 \\
\hline & OPD domain (OHIP-Edent) & $1.34(1.12-1.61)$ & 0.002 & $1.37(1.10-1.70)$ & 0.005 \\
\hline & Satisfaction with denture (No) & $1.22(0.51-2.97)$ & 0.655 & & \\
\hline
\end{tabular}

Correct classification for implant category predicted by model: maxilla $=72.1 \%$; mandible $=84.0 \%$ 
Table 4. Multinomial logistic regression for variables associated with preference for implant-retained overdenture (IOD) and implant fixed dentures (IFD) and conventional complete denture (CD) group as the reference category

\begin{tabular}{|c|c|c|c|c|c|c|c|c|}
\hline \multirow[b]{2}{*}{ Treatment } & \multirow[b]{2}{*}{ Variable } & \multirow[b]{2}{*}{ Categories } & \multicolumn{3}{|c|}{ Maxilla } & \multicolumn{3}{|c|}{ Mandible } \\
\hline & & & $\mathrm{B}(\mathrm{SE})$ & OR $(95 \% \mathrm{Cl})$ & $p$-value & $\mathrm{B}(\mathrm{SE})$ & OR $(95 \% \mathrm{Cl})$ & $p$-value \\
\hline \multirow[t]{6}{*}{ IOD } & Level of education & Lower & $-0.63(0.47)$ & $0.53(0.21-1.34)$ & 0.179 & $-1.04(0.53)$ & $0.35(0.13-1.00)$ & 0.050 \\
\hline & & Higher & 0 & & & 0 & & \\
\hline & Monthly income & Lower & $-1.01(0.92)$ & $0.36(0.06-2.22)$ & 0.273 & $-1.63(1.07)$ & $0.20(0.02-1.61)$ & 0.129 \\
\hline & & Intermediary & $-0.54(0.75)$ & $0.58(0.13-2.53)$ & 0.467 & $-0.99(0.93)$ & $0.37(0.06-2.28)$ & 0.285 \\
\hline & & Higher & 0 & & & & & \\
\hline & $\begin{array}{l}\text { OPD domain (OHIP- } \\
\text { Edent) }\end{array}$ & - & $0.27(0.10)$ & $1.31(1.07-1.60)$ & $0.010^{*}$ & $0.38(0.13)$ & $1.46(1.14-1.87)$ & $0.002^{*}$ \\
\hline \multirow[t]{6}{*}{ IFD } & Level of education & Lower & $-1.84(0.55)$ & $0.16(0.05-0.46)$ & $0.001^{*}$ & $-1.54(0.50)$ & $0.21(0.08-0.56)$ & $0.002^{*}$ \\
\hline & & Higher & 0 & & & 0 & & \\
\hline & Monthly income & Lower & $-1.85(0.86)$ & $0.16(0.03-0.86)$ & $0.032^{*}$ & $-2.44(0.98)$ & $0.09(0.01-0.60)$ & $0.013^{*}$ \\
\hline & & Intermediary & $-1,59(0.68)$ & $0.20(0.05-0.77)$ & $0.018^{*}$ & $-1.68(0.84)$ & $0.19(0.04-0.96)$ & $0.045^{*}$ \\
\hline & & Higher & 0 & & & & & \\
\hline & $\begin{array}{l}\text { OPD domain (OHIP- } \\
\text { Edent) }\end{array}$ & - & $0.90(0.12)$ & $1.09(0.87-1.37)$ & 0.439 & $0.26(0.12)$ & $1.30(1.02-1.64)$ & $0.031^{*}$ \\
\hline
\end{tabular}

